\title{
COMMENTARY
}

\section{A Call for Simplification and Integration of Doctor of Pharmacy Curricular Outcomes and Frameworks}

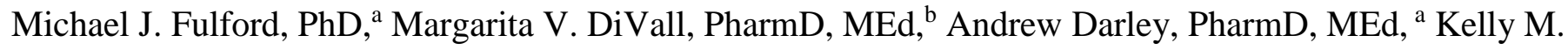 \\ Smith, PharmD ${ }^{\mathrm{a}}$ \\ ${ }^{\text {a }}$ The University of Georgia, College of Pharmacy, Athens, Georgia \\ ${ }^{\mathrm{b}}$ Northeastern University, School of Pharmacy, Boston, Massachusetts \\ Corresponding Author: Michael J. Fulford, The University of Georgia, College of Pharmacy, 250 West Green Str., Athens, GA \\ 30602. Tel: 706-542-5316. Email: mfulford@uga.edu.
}

Submitted October 21, 2021; accepted January 2, 2022; ePublished January 2022

Pharmacy education faces an upcoming revision of accreditation standards designed to outline degree program requirements for training the next generation of pharmacists. At the same time, pharmacy educators are increasingly expected to integrate multiple other educational frameworks and recommendations from distinct groups into their curricula. With this list of expectations constantly expanding and changing, education leaders are forced to spend valuable time and resources trying to satisfy "checklists" instead of enhancing their programs. The following commentary discusses concerns about the growing complexity of the standards and frameworks used in the accreditation process, overlap and redundancy in these various requirements, and relevant comparisons between pharmacy and medical education. We outline recommendations regarding purposeful integration of frameworks with the goal of simplifying accreditation requirements and enhancing program flexibility to deliver innovative, high-quality curricula.

Keywords: pharmacy education, reform, assessment, accreditation, CAPE 


\section{INTRODUCTION}

Pharmacy education sits at a crossroads. The Accreditation Council for Pharmacy Education (ACPE) is revising its accreditation standards for Doctor of Pharmacy (PharmD) programs after a revising them in 2016. ${ }^{1}$ The American Association of Colleges of Pharmacy (AACP) is revising the Center for the Advancement of Pharmacy Education (CAPE) domains after the 2013 version ${ }^{2}$ was adopted as the first four ACPE 2016 standards. At the same time, AACP is revising the list of Entrustable Professional Activities (EPAs) developed by its Academic Affairs Committee. ${ }^{3}$ These organizations are listening, meeting, and discussing with the goal of revising and developing new checklists and new expectations. They also are creating new stress for pharmacy educators. Why would processes like these worry pharmacy educators? Simply put, educators are concerned about additional requirements their school must meet to maintain full accreditation. These small task forces will interpret comments, concerns, and the future of pharmacy practice and will create a new framework or list of activities and expectations. Of additional concern is the continued lengthening of the accreditation standards without concern for the lack of resources available to enact these new checklists. Since most of these checklists overlap and offer much redundancy, educators are left shifting resources to meeting checklists versus innovating their curriculum.

Historically, sets of competencies, content checklists, and frameworks such as CAPE ${ }^{2}, \mathrm{EPAs}^{3}, \mathrm{ACPE}^{\mathrm{Standards}}$ Appendix 1, ${ }^{1}$ Appendix 2, Appendix 3, Interprofessional Education Collaborative (IPEC) core competencies ${ }^{4}$, and the Joint Commission of Pharmacy Practitioners (JCPP) Pharmacists' Patient Care Process ${ }^{5}$ have been developed by independent efforts. Groups and individuals have a clear purpose and rationale behind these initiatives and spend hours and hours of effort on their development. However, these disparate, convoluted models only heighten the perception and reality of pharmacy as heavily regulated, both within education and practice. As an Academy, we have failed to present these components in a way that is connected and integrated. We instead present them as literal checklists. These checklists manifest in rubrics and systems where myriads of documents are uploaded to demonstrate that a box is checked. We can no longer continue to increase the number and length of our checklists. Programs are drowning in data that are difficult to manage and act on and we have lost sight of what is important. Our students need to synthesize and integrate these components into their daily practice and our faculty need more time to be present with them during their education to ensure these components connect.

By using disparate groups to develop these frameworks and standards, we have become two-dimensional. Each task force and organization has come from its own lens and created exceptional work. However, without adding the dimensions of integration, synthesis, and taxonomy across frameworks and standards, educators are left weaving them together in complex curricular mapping efforts and providing evidence of achievement for every component. Educators with the unenviable task of creating a curriculum that meets all these checklists begin to question. How do these frameworks overlap? Do we need a list of EPAs? Are EPAs different from CAPE domains? Are CAPE domains different from ACPE Standards Appendix 1 (Appendix 1)? Is interprofessional education a truly disparate set of knowledge and skills? When considering the task of trying to identify relationships between the ever-expanding list of educational frameworks, we were reminded that in 2009, US General Stanley A. McChrystal was shown a figure meant to depict the complex nature of American military strategy in Afghanistan; the figure was a diagram comprised of multiple components and intersecting lines to indicate connections that looked similar to a plate of spaghetti. ${ }^{6}$ In response to this diagram, General McChrystal stated, "When we understand that slide, we'll have won the war." evolved, we have added layers of complexity to our educational frameworks in an effort to clarify expectations, advance the profession, and standardize outcomes. However, without a corresponding and intentional effort to simplify and integrate these frameworks, we are left with multiple distinct but overlapping components that are a challenge to fully understand and communicate to students, faculty, and key stakeholders.

Tyack and Cuban used the term "tinkering toward utopia" to describe educational reform in the United States. They suggest that our educational systems claim each new "reform" truly changes education and the next new thing will transform teaching and learning. However, they argue we never really change the core of education. Schools still put students in a room, with desks lined up facing the front where an identified expert presents information expecting students to hang on every word, absorb expertise, synthesize this information, and apply it to their chosen profession. Tyack and Cuban point out that in education, we have simply tinkered with parts and edges of educational systems. We have "flipped" classrooms and attempted to emphasize active learning. However, we essentially have not changed; we have just kept adding on. Why does this happen? Why can't we fully transform? Because transformation is too hard. It requires truly stripping down and letting go of old traditions. Educational reform is not a logical process. It is an emotional one. Ask anyone that has endured a curriculum revision. Enduring this emotional and difficult process of tearing down standards in pharmacy education and starting over makes it less feasible in reality. Therefore, our call to pharmacy education and especially AACP and ACPE is to focus on tinkering toward our PharmD utopia without adding more. We 
believe this can be accomplished by spending time integrating and weaving together these checklists. First, we need to understand where and how frameworks are overlapping and redundant. Additionally, critically evaluating how the growing complexity and rigor of preparing practice-ready pharmacists has impacted our current enrollment challenges and professional identity is imperative.

Appendix 1 of the ACPE Standards is a list of 37 content areas divided into 4 categories. ${ }^{1}$ ACPE standards directly state, "The clear expectation embedded within Appendix 1 is that students will develop the comprehensive knowledge base required to be 'practice ready' and that they will be able to retain, recall, build upon, and apply that knowledge to deliver quality patient care in a variety of entry-level practice settings." ${ }^{1}$ The standards clarify these required elements make up the core of what graduates should master upon completion of the PharmD.

ACPE adopts the CAPE domains as its first four standards which represent 15 high level domains of competency. ${ }^{1,2}$ The first standard, foundational knowledge directly refers to Appendix 1. Further comparison of Appendix 1 and ACPE standard 2 shows a direct overlap or alignment with the Appendix 1 topic list. Standards 3 and 4 can be found within the 37-topic list in Appendix 1. Only two CAPE domains are not specifically discussed in Appendix 1 (3.1 Problem Solving and 4.3 Innovation and Entrepreneurship). EPAs are suggested as simply a way to operationalize CAPE domains, so they certainly align and have redundancy with CAPE domains and thus Appendix $1 .^{3}$

Since EPAs are a model taken directly from medical school education, ${ }^{3}$ it is appropriate to compare the standards and frameworks provided by the Liaison Committee on Medical Education (LCME) and the Federation of State Medical Boards (FSMB) with pharmacy standards. ${ }^{8,9}$ There nine LCME standards that form the curricular content expectations. Additionally, LCME standards clarify that competencies and objectives are defined by the faculty of each school. LCME does not prescribe a list of specific objectives to educators. The FSMB standards of practice are about half as long as the National Association of Boards of Pharmacy (NABP) model practice act. ${ }^{10}$ The greatest difference between pharmacy and medical school standards is the flexibility in how they are achieved. FSMB sets standards, but leaves the details to State Boards while NABP is more prescriptive across multiple functional areas. In ACPE, we have continued to add lists and prescribe very specifically how things should be accomplished without much room for interpretation by programs. In LCME, more agency is given to the schools to demonstrate how they accomplish the standards. We argue that this freedom offers more opportunities for innovation. So, while we continue to add more lists, we take away more opportunities for creativity and curricular innovation at the program level. An argument could be made that if a PharmD program's graduates achieved the knowledge, skills, and abilities outlined in Appendix 1, they would essentially be developing practice-ready graduates. In fact, you might argue there would be no need for Standards 1, 2, 3, 4, or 11 (IPE) because these are already incorporated into Appendix 1. Appendix 2 provides direction on how experiences outlined in Standards 12 and 13 should be managed. ACPE's role is to provide basic guidance and frameworks for core content that is vital to being a practicing pharmacist. The Academy's role should be to generate and provide avenues and ideas for how schools can achieve the standards. That is why a focus on unification as it relates to the ACPE standards, rather than holding to disparate checklists, is paramount. The authors have developed a conceptual, visual representation of the alignment and integration of CAPE, EPAs, and Appendix 1 (Figure 1). This visual demonstrates the redundancy, accentuates the current mapping, and starts a conversation about how we can move away from disparate lists and work toward a comprehensive and intentional framework built on integration, synthesis, and levels of taxonomy. The model presented overlays the frameworks into one cohesive model. The core values and guiding principles in the preambles of these frameworks are internal and central the learner and evolve throughout their progression. These core values (CAPE Domain 4) inform the learner's approach to practice (CAPE Domain 3) which is demonstrated as they understand the larger context of patient care and pharmacy practice. As these cognitive and meta-cognitive abilities grow within and across these frames, learners build their foundation of knowledge (CAPE Domain $1 \&$ Appendix 1) which provides theoretical underpinnings for development of the essential skills in pharmacy practice (CAPE Domain 2 \& EPAs). Learning taxonomies can then serve to guide progression of outcomes toward being practice-ready. Last, there are 4 components we suggest are woven throughout these frames and provide a diversity, equity, and inclusion, interprofessional, systems-thinking, and patient-centered lens through which learners view their work. This model is merely one suggestion of trying to tie these frameworks together versus keeping them as separate, disparate, and regulated checklists.

We recommend that the expert groups and organizations that are currently undertaking these revisions work collaboratively to simplify, rather than increase the complexity of preparing future pharmacists. As individual curriculum committees struggle to focus on competency-based education and navigate bloated curricula where content gets added without taking anything away, we need the help of the experts in the Academy and our accrediting body to truly transform pharmacy education. We must redirect efforts of our faculty and administrators from ensuring all boxes are checked and 
all examination questions and rubrics are tagged to the continuously growing items we are trying to measure, and instead, to focus on the preparation of future pharmacists.

\section{REFERENCES}

1. Accreditation Council for Pharmacy Education. Accreditation Standards and Key Elements for the Professional Program in Pharmacy Leading to the Doctor of Pharmacy Degree ("Standards 2016"). Published February 2015. https://www.acpe-accredit.org/pdf/Standards2016FINAL.pdf. Accessed October 8, 2021.

2. Medina MS, Plaza CM, Stowe CD, et al. Center for the Advancement of Pharmacy Education 2013 educational outcomes. Am J Pharm Educ. 2013;77(8): Article 162.

3. Haines ST, Gleason BL, Kantorovich A, et al. Report of the 2015-16 Academic Affairs Standing Committee. Am J Pharm Educ. 2016; 80(9): Article S20.

4. Interprofessional Education Collaborative. Core competencies for interprofessional collaborative practice: 2016 update. https://ipec.memberclicks.net/assets/2016-Update.pdf Accessed October 8, 2021.

5. Joint Commission of Pharmacy Practitioners. Pharmacists' patient care process. https://jcpp.net/wpcontent/uploads/2016/03/PatientCareProcess-with-supporting-organizations.pdf. Accessed October 8, 2021.

6. Bumiller E. We have met the enemy and he is PowerPoint. New York Times. April 26, 2010. Accessed October 10, 2021. https://www.nytimes.com/2010/04/27/world/27powerpoint.html?smid=url-share

7. Tyack, David B, and Larry Cuban. Tinkering Toward Utopia: A Century of Public School Reform. Cambridge, Mass: Harvard University Press, 1995

8. Liaison Committee on Medical Education. Functions and structure of a medical school: Standards for accreditation of medical education programs leading to the MD degree. https://lcme.org/publications/ Published March 2021. Accessed October 8, 2021

9. Federation of State Medical Boards. Essentials of a state medical and osteopathic practice act. https://www.fsmb.org/siteassets/advocacy/policies/essentials-of-a-state-medical-and-osteopathic-practice-act.pdf. Published April 2015. Accessed October 13, 2021.

10. National Association of Boards of Pharmacy. Model State Pharmacy Act and Model Rules of the National Association of Boards of Pharmacy. https://nabp.pharmacy/resources/model-pharmacy-act/. Published August 2021. Accessed October 13, 2021. 
Figure 1

A Proposed Integration of Doctor of Pharmacy Curricular Outcome Frameworks

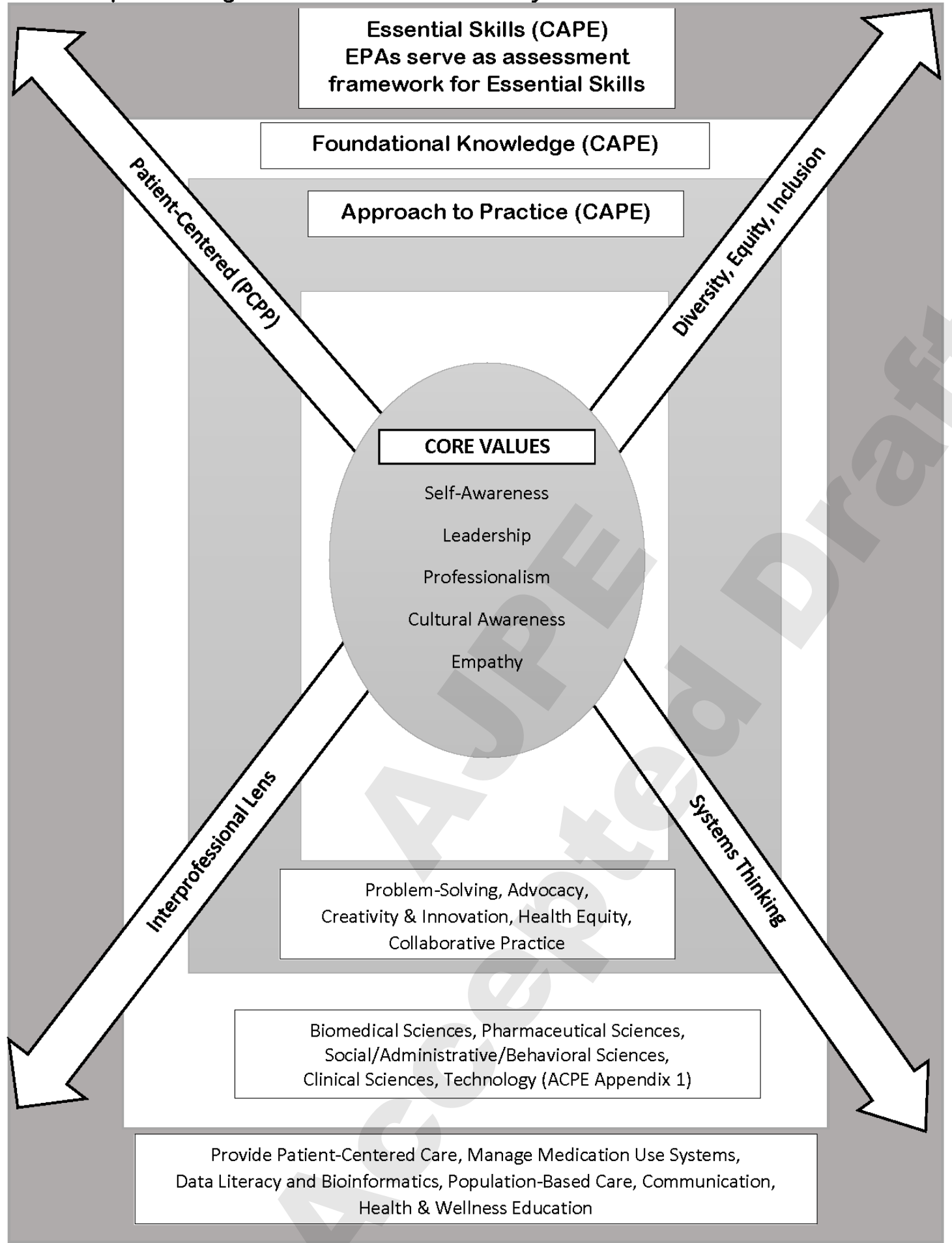

Figure 1 presents a model that overlays CAPE Domains, EPAs, and ACPE Appendix 1into one cohesive framework. Additional suggestions for changes in language and overall revision are added to better tie the frames together. The core values and guiding principles in the preambles of these frameworks are internal and central the learner and evolve throughout their progression. These core values (CAPE Domain 4) inform the learner's approach to practice (CAPE Domain 3) which is demonstrated as they understand the larger context of patient care and pharmacy practice. As these cognitive and meta-cognitive abilities grow within and across these frames, learners build their foundation of knowledge (CAPE Domain $1 \&$ Appendix 1) which provides theoretical underpinnings for development of the essential skills in pharmacy practice (CAPE Domain 2 \& EPAs). Learning taxonomies can then serve to guide progression of outcomes toward being practice-ready. Last, there are 4 components we suggest are 
woven throughout these frames and provide a diversity, equity, and inclusion, interprofessional, systems-thinking, and patient-centered lens through which learners view their work. This model is merely one suggestion of trying to tie these frameworks together versus keeping them as separate, disparate, and regulated checklists. 